\title{
The case for biology in the aetiology of anorexia nervosa ${ }^{1}$
}

It is now common to view anorexia nervosa as a multi-determined syndrome in which physical, psychological, family and sociocultural factors interact to produce the illness. Such a compromise position is difficult to refute. However, the components of this complex model neither explain nor account for the epidemiological and clinical features of the condition.

A popular cultural thesis is that the victim of anorexia nervosa is struggling to change her body in an attempt to deal with the contradictory requirements of the female role in late twentiethcentury Western societies (Chernin, 1986; Orbach, 1986; Edwards, 1987). However, this thesis cannot account for the numerous clear descriptions of the condition which date from the middle of the nineteenth century (Marcé, 1860; Gull, 1873; Lasègue, 1873), or even earlier (Morton, 1694).

A common assumption held by many who argue for the importance of socio-cultural factors, is that there have been marked increases in the incidence of anorexia nervosa, over the last two or three decades. The evidence that anorexia nervosa, as opposed to bulimic disorders, has increased in incidence in parallel with the vast social changes of the last two centuries is, however, controversial. Although there is no doubt that case registers show an increase in anorexia nervosa over the last few decades (Kendell et al. 1973; Jones et al. 1980; Szmukler et al. 1986; Willi et al. 1990) this is probably an artefact, due to increased awareness of the condition and recognition of its psychological basis. When rigorous case-finding procedures were used (Lucas et al. 1988) no significant trends in incidence were found in the 45 years spanning from 1930 to 1979 , although in a later paper which included the years 1980-5 a twofold increase in 15-24-year-old females was found (Lucas et al. 1991).

The vivid case descriptions of anorexia nervosa in Hong Kong (Lee, 1991) serve to remind us that the form of the illness does vary between cultures; 'fear of fatness', in particular, is not universal. It was argued, at the NIMH-sponsored conference on cultural issues for DSM-IV, that anorexia nervosa can be found in developing countries if this criterion is omitted (Littlewood, 1992). At the same conference the proposal to classify anorexia nervosa as a 'culture bound' category was rejected. It is possible that the prevalence of anorexia nervosa is reduced in non-Western cultures but definitive studies have not been performed; rather, there has been a large series of case reports (from Asia: Buhrich, 1981; Ong et al. 1982; Kope \& Sack, 1987; Khandelwal \& Saxena, 1990; Gandhi et al. 1991, and Africa: Nwaefuna, 1981; Buchan \& Gregory, 1984) and within ethnic minorities (Africans/USA/Caribbean/UK: Jones et al. 1980; Pumariega et al. 1984; Silber, 1984; Robinson \& Anderson, 1985; Thomas \& Szmukler, 1985; Holden \& Robinson, 1988) and Asians: Bryant-Waugh \& Lask, 1991; Mumford et al. 1991).

Family models of aetiology have inspired new approaches to treatment of anorexia nervosa in the last decade. Abnormal family interactions have been observed but whether these are either causal or specific is far from certain (Humphrey et al. 1986; Kog \& Vandereycken, 1989). An important deficit in both the familial and cultural models is the failure to account for individual susceptibility, which leads in some to the development of anorexia nervosa in the context of general environmental hazards.

A biological model of the aetiology of anorexia nervosa, although currently out of fashion, is not new (Russell, 1970). In the early part of the twentieth century there was diagnostic confusion between pituitary insufficiency and anorexia nervosa (McCullagh \& Tupper, 1940; Escamilla \& Lisser, 1942). Later, the hypothalamus was implicated in the origin of anorexia nervosa following

${ }^{1}$ Address for correspondence: Dr Janet Treasure, Institute of Psychiatry, De Crespigny Park, Denmark Hill, London SE5 8AF. 
observations that lesions of the lateral hypothalamus of rats lead to a life threatening avoidance of food (Anand \& Brobeck, 1951). More recently, data from twin studies suggest that genetic factors may account for a substantial part of susceptibility to anorexia nervosa (Holland et al. 1984, 1988; Treasure \& Holland, 1991). Thus, at the close of the twentieth century it is useful to re-examine the biological hypothesis.

\section{WHAT FEATURES SHOULD BE PRESENT IN A MODEL OF ANOREXIA NERVOSA?}

The features to be explained by any biological substrate include the following: $(a)$ a disturbance in the homeostatic control of appetite such that weight regulation is impaired (this is discussed in more detail below); (b) hypothalamic-pituitary gonadal and adrenal dysfunction (most of the other endocrine abnormalities and hypothalamic dysfunction can be simply explained as the sequela of weight loss); (c) the sex ratio (10:1 female:male) in the incidence of anorexia nervosa; $(d)$ the peripubertal time of onset; (e) the presence of psychosexual immaturity (Meyer, 1961; Crisp, 1967); and finally, $(f)$ the onset following psychological stress (Gull, 1873; Schmidt et al.'1992).

\section{THE CONTROVERSY ABOUT APPETITE IN ANOREXIA NERVOSA}

A problem with appetite and eating in anorexia nervosa may appear to be self-evident, but there is disagreement about whether appetite is disturbed. In the early accounts of anorexia nervosa (Lasègue, 1873; Gull, 1874) a lack of appetite was considered to be the primary disturbance. Ryle (1936) suggested that there was a "perpetuation of the initial loss of appetite by refusal of food until loss of appetite develops into a veritable revulsion against food'. However, recent psychiatric texts imply that the form of the illness has changed; Fairburn (1983) comments that 'their appetite for food persists (except in longstanding cases) and for this reason the term anorexia is inappropriate'. Certainly in underweight cases of anorexia nervosa, central (Kaye et al. 1988a, 1990a,b) and peripheral (Pirke et al. 1985; Ploog \& Pirke, 1987; Casper et al. 1988; Broberg \& Bernstein, 1989) physiological parameters which indicate 'biological' hunger are increased. However, evidence from experimental studies suggests that the identification and interpretation of these signals may be dysfunctional (Silverstone \& Russell, 1967; Coddington \& Bruch, 1970); ratings of hunger are lower and the perception of fullness is higher in patients with anorexia nervosa, compared with controls (Robinson et al. 1983; Hetherington \& Rolls, 1988, 1991). On the other hand, the preoccupation with food (supermarket gazing, cooking for others) and eating behaviours akin to those described in the literature of starvation (Keys et al. 1950; Solzhenitsyn, 1963; Vonnegut, 1969; Irvin, 1983) suggest that there is a psychological drive to eat but that this is either denied or is inadequate to compensate for the level of starvation present. There is no doubt that there is a profound disturbance in the homeostatic controls over nutritional state but the level of this dysfunction is unknown.

From the features which are described above it is reasonable to propose a model in which anorexia nervosa arises as a result of an abnormal interaction between sex steroids and the CNS system controlling appetite. Of all the neurotransmitter systems involved in the control of appetite, serotonin is of greatest interest as its spectrum of activity spans many of the clinical features noted above: moreover, many 5-HT pathways show sexual dimorphism. Morley \& Blundell (1988) highlighted the possibility that 5-HT and corticotrophin-releasing hormone were important candidates involved in the neurochemical aetiology of anorexia nervosa. More specifically, an animal model, immobilization-stress anorexia, which involves 5-HT pathways has been proposed as an analogue for human anorexic conditions (Donohoe, 1984; Dourish et al. 1987; Kennett et al. $1987 a, b)$.

\section{5-HYDROXYTRYPTAMINE AND APPETITE}

The evidence that 5-HT is critically important in appetite control comes from a wide variety of 
sources (see Blundell \& Hill, 1991; Curzon, 1992, for reviews). For example, D-fenfluramine decreases appetite and increases satiety probably by an effect on 5-HT-1C receptors (Hill \& Blundell, 1990, 1991; Curzon et al., 1992): this effect is countered by metergoline, a 5-HT receptor antagonist (Goodall \& Silverstone, 1988).

The control of appetite by 5 -HT shows quantitative differences between the sexes. Chronic fenfluramine infusion has a greater hypophagic effect in female than in male rats (Rowland, 1986). Repeated exposure to immobilization stress (see above) leads to a persistent reduction in food intake in female rats only (Kennett et al. 1986; Haleem et al. 1988). Furthermore, the hypophagic effects of M-chlorophenylpiperazine (M-CPP, a direct acting 5-HT agonist) and RU 24969 are greater in female than male rats deprived of food for 24 hours (Haleem, 1988). Overall, these studies suggest that the role of 5-HT in decreasing appetite is more pronounced in females. In humans also, sex hormones appear to influence the effect of 5-HT on appetite. For example, the effect of L-tryptophan and D-fenfluramine on food intake varies with the stage of the menstrual cycle (Leiter et al. 1987; Hill \& Blundell et al. 1991).

\section{5-HT AND STRESS}

In addition to its central role in appetite, 5-HT is involved in other behavioural responses analogous to the precipitating psychogenic factors in anorexia nervosa. Arousal and stress in rats increases central 5-HT release (Kalan et al. 1989; Dunn \& Welch, 1991). Immobilization-induced anorexia in the rat is reversed by 5-HT-1A agonists (Dourish et al. 1987). The endocrine response to prolonged chair restraint in monkeys (increased ACTH, and cortisol and reduced LH and testosterone levels) is similar to that found in anorexia nervosa (Norman \& Smith, 1991). It is interesting to note that in these animal models, female rats are more vulnerable to the behavioural effects of stress such as loss of appetite.

\section{5-HT LINKED NEUROENDOCRINE PATHWAYS}

5-HT linked neuroendocrine pathways also show sex-related differences. In women, but not men, weight loss enhances the release of prolactin in response to L-tryptophan (Goodwin et al. 1987). Prolactin release by $\mathrm{D}$-fenfluramine or buspirone is increased mid-menstrual cycle (Yatham et al. 1989; O'Keane \& Dinan, 1991). However, it has to be accepted that direct changes at the lactotroph cell or probably in dopaminergic systems may account for these effects: these issues require further investigation.

\section{5-HT AND SEXUAL FUNCTION}

Psychosexual immaturity and conflict about sexuality have been implicated in the development of anorexia nervosa (Janet, 1907; Waller et al. 1940; Beumont et al. 1981; Buvat-Herbaut et al. 1983). It is, therefore, interesting to note that 5-HT inhibits sexual behaviour in several species (Carter \& Davis, 197.7). Destruction of 5-HT pathways in the ventromedial hypothalamic nucleus with 5,6dihydroxytryptamine increases lordosis behaviour in rats (Luine et al. 1983), and the threshold dose of oestrogen needed to elicit this behaviour is lowered (Luine et al. 1987). Both oestrogen priming and destruction of 5-HT neurons lead to an increase of dendritic spines on ventromedial hypothalamic neurons (Frankfurt \& McEwen, 1991).

\section{5-HT AND BEHAVIOURAL STYLE}

In Cloninger's (1987) theoretical model of personality, harm avoidance, a form of behavioural inhibition, is considered to result from abnormal central 5-HT function. We have found subjects with anorexia to have elevated scores on this dimension (O'Dwyer et al. 1992). Anorexia nervosa is characterized by high levels of control and perfectionism (Casper et al. 1990), which contrast 
markedly with the impulsive, aggressive and suicidal behaviours associated with low levels of 5hydroxyindoleacetic acid (5-HIAA) in cerebrospinal fluid and blunted 5-HT neuroendocrine function (Traskamn et al. 1981; Linnoila et al. 1983; O'Keane 1992). In summary, 5-HT pathways could account for the behavioural inhibition and control observed in anorexia nervosa.

\section{5-HT IN ANOREXIA NERVOSA}

Interpretation of studies of the pathophysiology of anorexia nervosa is difficult as weight, nutritional and menstrual status are often confounding variables (i.e. some of the apparently discrepant findings in the literature arise because observed changes may be a result rather than a cause of the illness). Thus, although a theoretical model of anorexia nervosa would implicate increased hypothalamic release of 5-HT (Morley et al. 1986; Morley \& Blundell, 1988), there are reports that in anorexia nervosa plasma tryptophan levels are reduced (Coppen et al. 1976; Johnston et al. 1984) as are CSF levels of 5-HIAA (Kaye et al. 1988 b). Interestingly, however, longterm weight-restored anorexic subjects have elevated concentrations of CSF 5-HIAA compared with controls (Kaye et al. 1991). The same problems of data interpretation arise when the literature on endocrine responses is examined. McBride et al. (1991), using DL-fenfluramine, found reduced and delayed release of prolactin in women with eating disorders at low weight (i.e. these studies suggest that 5-HT mediated prolactin release is decreased in subjects with anorexia nervosa at low weight). Brewerton et al. (1990) have also shown that compared with normal controls, women with anorexia nervosa have reduced prolactin responses to both L-tryptophan and $\mathrm{M}$-CPP, in an emaciated state. However, in addition, they have reported that these diminished responses persist after the achievement of goal weight. (It should be emphasized that goal weight is not necessarily normal weight.) On the other hand, Goodwin et al. (1989) found no abnormality in prolactin release in response to L-tryptophan in underweight patients with anorexia nervosa. Thus, overall, the clinical picture remains unclear.

\section{CONCLUSION}

It is reasonable to propose that the underlying abnormality in anorexia nervosa is related to an increase rather than a decrease in 5-HT mediated responses and that weight loss obscures this abnormality. A predisposition towards overactivity in 5-HT pathways could plausibly account for the clinical and epidemiological features of the condition. Furthermore, fluxes in oestrogen or other sex hormones may be necessary to reveal this vulnerability.

Further studies in which the confounding effects of weight nutritional and sex hormone status are controlled, as in patients following recovery, are needed to test this hypothesis.

J. TREASURE AND I. CAMPBELL

\section{REFERENCES}

Anand, B. K. \& Brobeck, J. R. (1951). Localisation of a 'feeding center' in hypothalamus of the rat. Proceedings of the Society for Experimental Biology and Medicine 77, 323-324.

Beumont, P. J. V., Abrahams, S. F. \& Simson, K. G. (1981). The psychosexual histories of adolescent girls and young women with anorexia nervosa. Psychological Medicine 11, 131-140.

Blundell, J. E. \& Hill, A. J. (1991). Serotonin, eating disorders and the satiety cascade. In Serotonin-related Psychiatric Syndromes: Clinical and Therapeutic Links (ed. C. B. Cassano and H. S. Akiskal), pp. 125-129. Royal Society of Medicine, Services International Congress and Symposium. Series No: 165.

Brewerton, T. D., Mueller, E. A., Brandt, H. A., Lesem, D., Murphy, D. L. \& Jimerson, D. C. (1990). Serotonin in eating disorders. In Serotonin in Major Psychiatric Disorders (ed. E. F. Coccaro and D. L. Murphy), pp. 155-184. American Journal of Psychiatry Press: Washington, DC.
Broberg, D. J. \& Bernstein, I. L. (1989). Cephalic insulin release in anorexic women. Physiology and Behavior 45, 871-874.

Bryant-Waugh, R. \& Lask, B. (1991). Anorexia nervosa in a group of Asian children living in Britain. British Journal of Psychiatry 158, 229-233.

Buchan, T. \& Gregory, L. D. (1984). Anorexia nervosa in a black Zimbabwean. British Journal of Psychiatry 145, 326-330.

Buhrich, N. (1981). Frequency of presentation of anorexia nervosa in Malaysia. Australian and New Zealand Journal of Psychiatry 15, 153-155.

Buvat-Herbaut, M., Hebbinchuys, P., Lemaire, A. \& Buvat, J. (1983). Attitudes towards weight, body image, eating, menstruation, pregnancy and sexuality in 81 cases of anorexia nervosa compared to 281 normal control school girls. International Journal of Eating Disorders 2, 45-59.

Carter, A. \& Davis, S. T. (1977). Biogenic amines, reproductive hormones and female sexual behaviour. A review. Behavioural Research 1: 213-225. 
Casper, R. C. (1990). Personality features of women with good outcome from restricting anorexia nervosa. Psychosomatic Medicine 52, 156-170.

Casper, R. C., Pandy, G. N., Jaspan, J. B. \& Rubenstein, A. H. (1988). Hormone and metabolite plasma levels after oral glucose in bulimia and healthy controls. Biological Psychiatry 24, 663-674.

Chernin, K. (1986). The Hungry Self. Virago: London.

Cloninger, C. R. (1987). A systematic model for clinical description and classification of personality variants: a proposal. Archives of General Psychiatry 44, 573-588.

Coddington, R. D. \& Bruch, H. (1970). Gastric perceptivity in normal, obese and schizophrenic subjects. Psychosomatics 11, 571-579.

Coppen, A. J., Gupta, R. K., Eccleston, E. G., Wood, K. M. \& Wakeling, A. (1976). Plasma tryptophan in anorexia nervosa. Lancet i, 961.

Crisp, A. H. (1967). The possible significance of some behavioural correlates of weight and carbohydrate intake. Journal of Psychosomatic Research 11, 117-131.

Curzon, G. (1992). Serotonin and eating disorders: pharmacological relationships. International Academy of Biomedical Drug Research 1. 112-128.

Donohoe, T. P. (1984). Stress-induced anorexia: implications for anorexia nervosa. Life Sciences 34, 203-218.

Dourish, C. T., Kennett, G. A. \& Curzon, G. (1987). The 5-HT-1A agonists 8-OH-DPAT, buspirone and ipsapirone attenuate stressinduced anorexia in rats. Journal of Psychopharmacology 1, 23-31.

Dunn, A. J. \& Welch, J. (1991). Stress and endotoxin-induced increases in brain tryptophan and serotonin metabolism depend on sympathetic nervous system activation. Journal of Neurochemistry $57,1615-1622$

Edwards, G. (1987). Anorexia and the family. In Fed Up and Hungry: Women. Oppression and Food (ed. M. Lawrence), pp. 33-41. Women's Press: London.

Escamilla, R. F. \& Lisser, H. (1942). 'Simmond's disease'. Journal of Clinical Endocrinology 2, 65.

Fairburn, C. G. (1983). Eating disorders. In Companion to Psychiatric Studies (ed.R. E. Kendell and A. K. Zealley), pp. 535-547. Churchill Livingstone: Edinburgh.

Frankfurt, M. \& McEwen, B.S. (1991). 5,7-Dihydroxytryptamine and gonadal steroid manipulation alter spine density in ventromedial hypothalamic neurons. Neuroendocrinology 54, 654-657.

Gandhi, D. H., Prakash Appaya, M. \& Machado, T. (1991). Anorexia nervosa in Asian children. British Journal of Psychiatry 159, $591-592$.

Goodall, E. \& Silverstone, T. (1988). Differential effect of Dfenfluramine and metergoline on food intake in human subjects. Appetile 11, 215-228.

Goodwin, G. M., Fairburn, C. G. \& Cowen, P. J. (1987). The effects of dieting and weight loss on neuroendocrine responses to tryptophan, clonidine and apomorphine in volunteers. Archives of General Psychiatry 44, 952-955.

Goodwin, G. M., Shapiro, C. M., Bennie, J., Dick, H., Carroll, S. \& Fink, G. (1989). The neuroendocrine responses and psychological effects of infusion of L-tryptophan in anorexia nervosa. Psychological Medicine 19, 857-864.

Gull, W. W. (1873). Proceedings of the Clinical Society of London. British Medical Journal i, 527-529.

Haleem, D. J. (1988). Serotoninergic functions in rat brain: sexrelated differences and responses to stress. Ph.D. thesis, University of London.

Haleem, D. J., Kennett, G. A. \& Curzon, G. (1988). Adaptation of female rats to stress: shift to male pattern by inhibition of corticosterone synthesis. Brain Research 458, 339-347.

Hetherington, M. M. \& Rolls, B. J. (1988). Sensory-specific satiety and food intake in eating disorders. In Eating Behaviour in Eating Disorders (ed. B. T. Walsh), pp. 141-160. American Psychiatric Press: Washington, DC.

Hetherington, M. M. \& Rolls, B. J. (1991). Eating behaviour in eating disorders: response to preloads. Physiology and Behaviour 50, 101-108.
Hill, A. J. \& Blundell, J. E. (1990). Sensitivity of the appetite control system in obese subjects to nutritional and serotoninergic challenges. International Journal of Obesity 14, 219-233.

Hill, A. J. \& Blundell, J. E. (1991). Food selection, body weight and the premenstrual syndrome (PMS). Effect of D-fenfluramine. (Abstr.) International Journal of Obesity 15, 215.

Holden, N. L. \& Robinson, P. H. (1988). Anorexia nervosa and bulimia nervosa in British blacks. British Journal of Psychiatry 152 , 544-549.

Holland, A. J., Hall, A., Murray, R., Russell, G. F. M. \& Crisp, A. (1984). Anorexia nervosa: a study of 34 twin pairs and one set of triplets. British Journal of Psychiatry 145, 414-419.

Holland, A. J., Sicotte, N. \& Treasure, J. L. (1988). Anorexia nervosa: evidence for a genetic basis. Journal of Psychosomatic Research 32, 561-571.

Humphrey, L. L., Apple, R. F. \& Kirschenbaum, D. S. (1986). Differentiating bulimic-anorexic from normal families using interpersonal and behavioural observational systems. Journal of Consulting and Clinical Psychology 54, 190-195.

Irvin, L. (1983). Castaway. Penguin: London.

Janet, P. (1907). The Major Symptoms of Hysteria. Macmillan: London.

Johnston, J. L., Leiter, L. A., Burrow, G. N., Garfinkel, P. E. \& Anderson, G. H. (1984). Excretion of urinary catecholamine metabolites in anorexia nervosa: effect of body composition and energy intake. American Journal of Clinical Nutrition 40, 10011006.

Jones, D. J., Fox, M. M., Babigan, H. M. \& Hutton, H. E. (1980). Epidemiology of anorexia nervosa in Munroe County, New York: 1960-1976. Psychosomatic Medicine 42, 551-558.

Kalan, P., Rosegren, E., Lindvall, O. \& Bjorklund, A. (1989). Hippocampal noradrenaline and serotonin release over 24 hours as measured by the dialysis technique in freely moving rats: correlation to behavioural activity state, effect of handling and tail pinch. European Journal of Neuroscience 1, 181-188.

Kaye, W. H., Gwirtsman, H. E., Brewerton, T. D., George, D. T. \& Wurtman, R.J. (1988a). Bingeing behavior and plasma amino acids: a possible involvement of brain serotonin in bulimia nervosa. Psychiatry Research 23, 31-43.

Kaye, W. H., Gwirstman, H. E., George, D. T., Jimerson, D. C. \& Ebert, M. H. (1988b). CSF 5-HIAA concentrations in anorexia nervosa: reduced values in underweight subjects normalise after weight gain. Biological Psychiatry 23, 102-105.

Kaye, W. H., Ballenger, J. C., Lydiard, R. B., Stuart, G. W., Laraia, M. T., O'Neil, P., Fossey, M. D., Stevens, V., Lesser, S. \& Hsu, G. $(1990 a)$. CFS monoamine levels in normal-weight bulimia: evidence for abnormal noradrenergic activity. American Journal of Psychiatry 147, 225-229.

Kaye, W. H., Berrettini, W., Gwirtsman, H. \& George, D. T. $(1990 \mathrm{~b})$. Altered cerebrospinal fluid neuropeptide $Y$ and peptide YY immunoreactivity in anorexia and bulimia nervosa. Archives of General Psychiatry 47, 548-556.

Kaye, W. H., Gwirstman, H. E., George, D. T. \& Ebert, M. H. (1991). Altered serotonin activity in anorexia nervosa after longterm weight restoration. Archives of General Psychiatry 48, 556-562.

Kendell, R. E., Hall, D. J. \& Hailey, A. (1973). The epidemiology of anorexia nervosa. Psychological Medicine 3, 200-203.

Kennett, G. A., Chaouloff, F., Marcou, M. \& Curzon, G. (1986). Female rats are more vulnerable than males in an animal model of depression: the possible role of serotonin. Brain Research 382, 416-421.

Kennett, G. A., Dourish, C. T. \& Curzon, G. (1987a). 5-HT (1B) agonists induce anorexia at a post-synaptic site, 5-HT (1A) agonists cause hyperphagia. European Journal of Pharmacology 141, 429-435.

Kennett, G. A., Dourish, C. T. \& Curzon, G. (1987b). Antidepressant-like action of 5-HT-1A agonists and conventional antidepressants in an animal model of depression. European Journal of Pharmacology 134, 265-274.

Keys, A., Brozak, J., Henshall, A., Mickelson, O. \& Taylor, H. L. 
(1950). The Biology of Human Starvation, Vol II, pp. 850-857. University of Minnesota Press: Minneapolis.

Khandelwal, S. K. \& Sazena, S. (1990). Anorexia nervosa in people of Asian extraction. British Journal of Psychiatry 157, 784.

Kog, E. \& Vandereycken, W. (1989). Family interaction in eating disorder patients and normal controls. International Journal of Eating Disorders 8, $11-23$.

Kope, T. M. \& Sack, W. H. (1987). Anorexia nervosa in Southeast Asian refugees: a report on three cases. Journal of the American Academy of Child and Adolescent Psychiatry 26, 795-796.

Lasègue, E. C. (1873). On hysterical anorexia. Medical Times Gazette 2, 265-269.

Lee, S. (1991). Anorexia nervosa in Hong Kong: a Chinese perspective. Psychological Medicine 21, 703-712.

Leiter, L. A., Huboticky, N. \& Anderson, G. H. (1987). Effects of $L-$ tryptophan on food intake and selection in lean men and women. Annals of the New York Academy of Sciences 499, 327-328.

Linniola, M., Virkkunen, M., Scheinin, M., Nuutila, A., Rimon, R. \& Goodwin, F. K. (1983). Low cerebrospinal fluid 5-HIAA concentration differentiates impulsive from non-impulsive violent behaviour. Life Sciences 33, 2609-2614.

Littlewood, R. (1992). DSM-IV and culture: is the classification internationally valid? Psychiatric Bulletin 16, 257-261.

Lucas, A. R., Beard, C. M., O'Fallon, W. M. \& Kurland, L. T. (1988). Anorexia nervosa in Rochester, Minnesota: a 45-year study. Mayo Clinic Proceedings 63, 433-442.

Lucas, A. R., Beard, M. C., O'Fallon, M.W. \& Kurland, L. T. (1991). 50-year trends in the incidence of anorexia nervosa in Rochester, Minn.: a population-based study. American Journal of Psychiatry 148, 917-922.

Luine, V. N., Frankfurt, M., Rainbow, T. C., Biegon, A. \& Asmitia, E. (1983). Intrahypothalamic 5,7-dihydroxytryptamine facilitates feminine sexual behaviour and decreases (H)imipramine binding and S-HT uptake. Brain Research 264, 344-348.

Luine, V. N., Thornton, J. E., Frankfurt, M. \& MacLusky, N. J. (1987). Effects of hypothalamic serotonin depletion on lordosis behaviour and gonadal hormone receptors. Brain Research 426, 47-54.

McBride, P. A., Anderson, G. M., Khait, V. D., Sunday, S. R. \& Halmi, K. A. (1991). Serotoninergic responsivity in eating disorders. Psychopharmacology Bulletin 27, 365-372.

McCullagh, E. P. \& Tupper, W. R. (1940). 'Anorexia Nervosa'. Annals of International Medicine 14, 817-821.

Marcé, L. A. (1860). On a form of hypochondriacal delirium occurring consecutive to dyspepsia and characterized by refusal of food. Journal of Psychological Medicine and Mental Pathology 13, 204-206.

Meyer, J. E. (1961). Das Syndrom der Anorexia Nervosa: Katamnestische Untersuchungen. Archiv für Pschychiatrie und Nervenkrankheiten und Zeitschrift für die Gesämte Neurologie und Psychiatrie 202, 31-59.

Morley, J. E. \& Blundell, J. E. (1988). The neurobiological basis of eating disorders: some formulations. Biological Psychiatry 23, 53-78.

Morley, J. E., Levine, A. D. \& Willenberg, M. L. (1986). Stressinduced feeding disorders. In Pharmacology of Eating Disorders: Theoretical and Clinical Developments (ed. M. A. Carruba and J. E. Blundell), pp. 71-99. Raven Press: New York.

Morton, R. (1694). Phthisiologia-Or a Treatise of Consumptions. Smith \& Walford: London.

Mumford, D. B., Whitehouse, A. M. \& Platts, M. (1991). Eating disorders among Asian schoolgirls in Bradford: socio-cultural correlates. British Journal of Psychiatry 158, 222-228.

Norman, R. L. \& Smith, C. J. (1991). Restraint inhibits luteinizing hormone and testosterone secretion in intact male rhesus macaques: effects of concurrent naloxone administration. Neuroendocrinology 55, 405-415.

Nwaefuna, A. (1981). Anorexia nervosa in a developing country. British Journal of Psychiatry 138, 270-271.

O'Dwyer, A. \& Treasure, J. (1992). Assessment of the tridimensional personality questionnaire in eating disorders: is it a useful investigative tool? Presentation at Royal College of Psychiatrists Annual Meeting, Dublin.

O'Keane, V. \& Dinan, T. G. (1991). Prolactin and cortisol responses to $D$-fenfluramine in major depression: evidence for diminished responsivity of central serotoninergic function. American Journal of Psychiatry 148, 1009-1015.

O'Keane, V., O'Hanlon, M. \& Webb, M. (1991). Prolactin responses throughout the menstrual cycle: evidence for an oestrogen-induced alteration. Clinical Endocrinology 34, 289-292.

O'Keane, V., Moloney, E., O'Neill, H., O'Connor, A., Smith, C. \& Dinan, T. G. (1992). Blunted prolactin responses to D-fenfluramine in sociopathy. Evidence for sub-sensitivity of central serotoninergic function. British Journal of Psychiatry 160, 643-646.

Ong, Y. L., Tsoi, W. F. \& Cheah, J.S. (1982). A clinical and psychosocial study of seven cases of anorexia nervosa in Singapore Singapore Medical Journal 23, 255-261.

Orbach, S. (1986). Hunger Strike. Penguin: London.

Pirke, K. M., Pahl, J., Schweiger, V. \& Warnhoff, M. (1985). Metabolic and endocrine indices of starvation in bulimia: a comparison with anorexia nervosa. Psychiatric Research 15, 33-39.

Ploog, D. W. \& Pirke, K. M. (1987). Psychobiology of anorexia nervosa. Psychological Medicine 17, 843-859.

Pumariega, A. J., Edwards, P. \& Mitchell, C. B. (1984). Anorexia nervosa in black adolescents. Journal of the American Academy of Child and Adolescent Psychiatry 23, 111-114.

Robinson, P. \& Andersen, A. (1985). Anorexia nervosa in American blacks. Journal of Psychosomatic Research 19, 183-188.

Robinson, R. G., Tortosa, M. \& Sullivan, J. (1983). Quantitative assessment of psychological state in patients with anorexia nervosa or bulimia: response to caloric stimulus. Psychosomatic Medicine 45, 283-291.

Rowland, N. E. (1986). Effect of continuous infusions of dexfenfluramine on food intake, body weight and brain amines in rats. Life Sciences 39, 2581-2586.

Russell, G. F. M. (1970). Anorexia nervosa: its identity as an illness treatment. In Modern Trends in Psychological Medicine (ed. J. E. Price), pp. 131-164. Butterworth: London.

Ryle, J. A. (1936). Anorexia nervosa. Lancet ii, 893-899.

Schmidt, U., Tiller, J. M. \& Treasure, J. L. (1992). The role of life events and difficulties in the onset of eating disorders. Psychiatric Bulletin (Suppl. 4).

Silber, T. (1984). Anorexia nervosa in black adolescents. Journal of the National Medical Association 76, 29-32.

Silverstone, T. \& Russell, G. F. M. (1967). 'Gastric hunger' contractions in anorexia nervosa. British Journal of Psychiatry 113, 257-263.

Solzhenitsyn, A. (1963). On Day in the Life of Ivan Denisovitch. Penguin: London.

Szmukler, G., McCance, C. \& McCrone, L. (1986). Anorexia nervosa: a psychiatric case register study from Aberdeen Psychological Medicine 16, 49-58.

Thomas, J. P. \& Szmukler, G. I. (1985). Anorexia nervosa in patients of Afro-Caribbean extraction. British Journal of Psychiatry 146, 653-656.

Traskamn, S., Asberg, M., Bertilsson, L. \& Sjostrrand, L. (1981). Monoamine metabolites in CSF and suicidal behaviour. Archives of General Psychiatry 38, 631-636.

Treasure, J. L. \& Holland, A. J. (1991). Genes and aetiology of eating disorders. In The New Genetics of Mental Illness (ed. P. McGuffin and R.M. Murray), pp. 198-211. Butterworth-Heinemann: Oxford.

Vonnegut, K. (1969). Slaughterhouse 5. Penguin: London.

Waller, J. V., Kaufman, R. M. \& Deutsch, F. (1940). Anorexia nervosa: a psychosomatic entity. Psychosomatic Medicine 2, 3-16. Willi, J., Giacometti, G. \& Limacher, B. (1990). Update on the epidemiology of anorexia nervosa in a defined region of Switzerland. American Journal of Psychiatry 147, 1514-1517.

Yatham, L. N., Barry, S. \& Dinan, T. G. (1989). Serotonin receptors, buspirone and premenstrual syndrome. Lancet i, 1447-1448. 